\title{
Oxidative Carbonylation of 2-Propyn-1-ol and 2-Methyl-3-butyn-2-ol in an Oscillatory Mode
}

\author{
Sergey Nikolaevich Gorodsky \\ Department of Basic Organic Synthesis, Lomonosov Moscow State University of Fine Chemical Technologies (MITHT), \\ Vernadsky Avenue 86, 119571 Moscow, Russia \\ Correspondence should be addressed to Sergey Nikolaevich Gorodsky, gorodsky@yandex.ru
}

Received 31 October 2011; Accepted 18 January 2012

Academic Editor: Dipakranjan Mal

Copyright ( $) 2012$ Sergey Nikolaevich Gorodsky. This is an open access article distributed under the Creative Commons Attribution License, which permits unrestricted use, distribution, and reproduction in any medium, provided the original work is properly cited.

The oscillatory modes of oxidative carbonylation reaction of two new substrates-2-methyl-3-butyn-2-ol and 2-propyn-1-ol in homogeneous system $\mathrm{PdI}_{2}-\mathrm{KI}-\mathrm{CO}-\mathrm{O}_{2}-\mathrm{CH}_{3} \mathrm{OH}$ are found. Borders of oscillatory areas are drawn, the basic products of reaction are identified, and probable processes routes are offered.

\section{Introduction}

The phenomenon of intermediates concentration oscillations is found already in several tens of homogeneous [1] and heterogeneous [2] chemical systems. The most interesting thing, in our opinion, is the oscillations occurring in homogeneous catalysis conditions. They are evolving out of intermediates complex interactions, which are formed during process. So this type of oscillations has a chemical nature only. Influence of diffusion, processes of mass and heat exchange, certainly, can be observed in these systems, but these processes, to all appearance, are not responsible for an occurrence of concentration oscillations in the homogeneous systems.

We were lucky to find out oscillatory modes of oxidative carbonylation reactions of two new alkynes: 2-methyl-3butyn-2-ol (MB) and 2-propyn-1-ol (P). As far as we know it is the first mention of oscillatory process with participation of oxygen containing alkynes in metal complexes catalysis conditions. In early works we investigated the oscillations in palladium halogenide solutions in reactions of alkynes oxidative carbonylation [3-11]. These are examples of reactions in which complex products-carboxylic acids and their derivatives-are synthesized from simple substances- $\mathrm{H}_{2} \mathrm{O}$, $\mathrm{CH}_{3} \mathrm{OH}, \mathrm{CO}$, and so on. The carbonylation reactions are interesting with relation to important products of organic synthesis obtaining 2-methyl-3-butyn-2-ol is that used as semiproduct in synthesis of fragrance compounds, medical products, and vitamins, applied as anticorrosive means to protection of the petroleum equipment, the modifier of motor fuels, emulgators. MB is an interesting research object. On the one hand, it has triple bond in the molecule, and so it can participate in reactions of hydrogenation, halogenations and other addition processes on the triple bond. It is active also in reactions of oligomerization and polymerization, and owing to presence of hydroxyl groups MB is the participant of reactions that are characteristic for alcohols generally, and for tertiary alcohols particularly. Finally, MB participates in reactions of carbonylation as any unsaturated reactant. $\mathbf{M B}$ reacts in butanol with nickel carbonyl in the presence of $\mathrm{HCl}$ even at room temperature and gives as main product butylic ether of 4-hydroxy-4-methyl-2-pentenoic acid with a good yield [12]. After the further hydrogenation and hydrolysis, isohexane acid and corresponding lactone (1). 


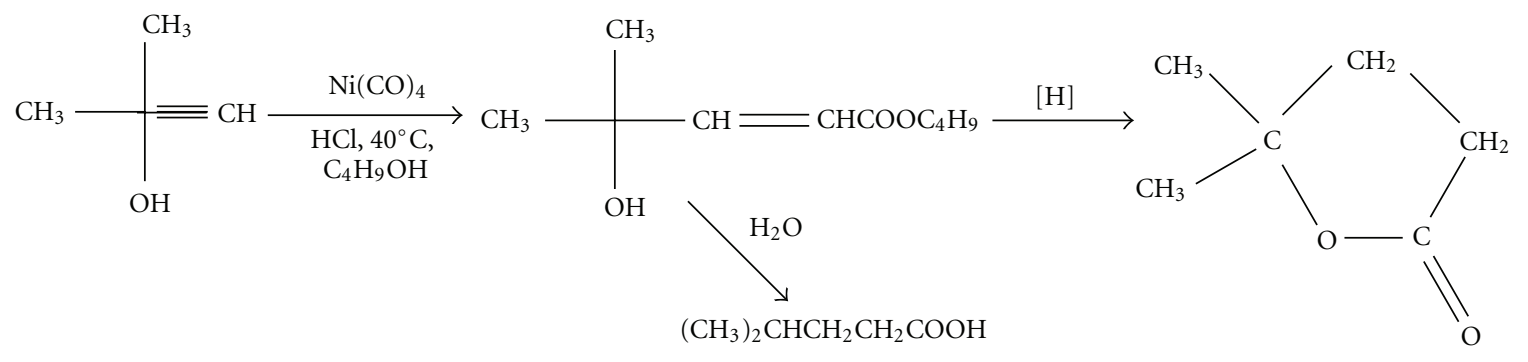

In paper [13] are formed about the dimethylitaconic anhydride synthesis (2) in carbonylation of MB process: in Pd, $\mathrm{Rh}$, or Re solutions as catalysts is reported a compound was obtained in (2) (b.p. $=95-100^{\circ} \mathrm{C}$ ) with $60 \%$ yield, whose hydrolysis has resulted in teraconic acid (b.p. $=162-163^{\circ} \mathrm{C}$ ).<smiles>CC(C)=C1CC(=O)OC1=O</smiles>

2-propyn-1-ol is an initial reagent for synthesis of some important industrial products. At oxidative dimerization of P 2,4-hexadiyn-1,6-diol is formed, which is converted by the subsequent hydrogenation into 2,4-hexadyen-1,6-diol, an initial product for synthesis of softeners and esters. Hydrogenation of $\mathbf{P}$ gives an allyl and $n$-propyl alcohols [14].

Propargyl bromide $\left(\mathrm{HC} \equiv \mathrm{CHCH}_{2} \mathrm{Br}\right)$ obtained from $\mathbf{P}$ is used as solvent of polyamides and cellulose acetates, corrosion inhibitor, and intermediate in processes of vitamin A and pesticides synthesis [14].

The paths of $\mathbf{P}$ transformation in carbonylation reactions are rather various. So, in ethanol solutions of nickel carbonyl in the presence of an inorganic acid at $40^{\circ} \mathrm{C}$ a stoichiometric process occurs (3), which gives $\alpha$-substituted esters of acrylic acid [15]:

$$
4 \mathrm{CH} \equiv \mathrm{CCH}_{2} \mathrm{OH}+\mathrm{Ni}(\mathrm{CO})_{4}+4 \mathrm{C}_{2} \mathrm{H}_{5} \mathrm{OH}+2 \mathrm{HCl} \longrightarrow \underset{\mathrm{COOC}_{2} \mathrm{H}_{5}}{\operatorname{l}} \longrightarrow \mathrm{HOCH}_{2} \mathrm{C}=\mathrm{CH}_{2}+\mathrm{NiCl}_{2}+\mathrm{H}_{2}
$$

$\alpha$-substituted acrylic acids are formed in water on the same conditions. $\mathbf{P}$ carbonylation in ethanol in the presence of $\mathrm{H}_{2} \mathrm{SO}_{4}$ at $55^{\circ} \mathrm{C}$ with stoichiometric amounts of $\mathrm{Ni}(\mathrm{CO})_{4}$ with the subsequent etherification results in ethyl- $\alpha$-(hydroxymethyl)-acrylate formation with a $58 \%$ yield and ethyltrans- $\gamma$-hydroxycrotonate with an $11 \%$ yield [16]. The last product is interesting because its formation occurs with a formal addition of the fragments of the formic acid against the Markovnikov's rule.

$\mathbf{P}$ etherifies in the presence of $\mathrm{Pd} / \mathrm{C}$, and $\mathrm{HCl}$ catalysts in methanol at $100^{\circ} \mathrm{C}$ into esters of itaconic and aconitic acids (4) [13]:

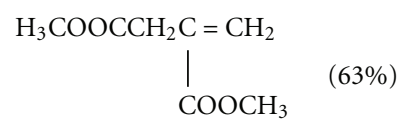

$\left.\right|_{\mathrm{COOCH}_{3}} ^{\mathrm{H}_{3} \mathrm{COOCCH}_{2} \mathrm{C}}=\mathrm{CHCOOCH}_{3}$ 
Hydrolysis of esters allows obtaining itaconic and aconitic acids. The first one passes easily into itaconic anhydride that turns sequentially by hydrogenation into methylsuccinic acid (5).

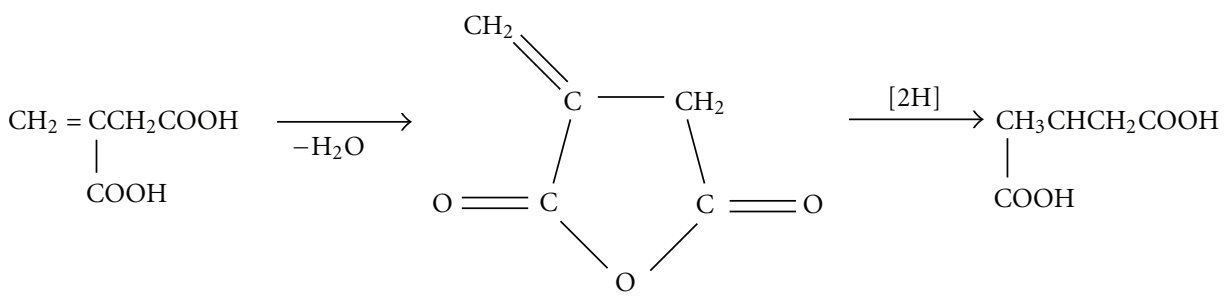

\section{Experiments}

Experiments on oxidative carbonylation MB were carried out in closed system at $40^{\circ} \mathrm{C}$ in glass thermostatic reactor (volume $=200 \mathrm{~mL}$ ), having a reflux condenser, a liquid sampling unit, and units for glass and platinum electrodes, electrolytic key, and graduated gas burette.

Gas and liquid phases were stirred with a magnetic stirrer. The measurements of the electric potential differences $\left(E_{\mathrm{Pt}}\right)$ and the acidity of the reaction solution $(\mathrm{pH})$ were managed with platinum and glass electrodes accordingly during experiments. Silver-chloride electrode was used as a reference electrode; it was immersed in the saturated solution of $\mathrm{KCl}$, and connected to the reactor via an electrolytic bridge filled with the colloidal (agar) solution of KI in methanol. For measurement of $\mathrm{pH}$ and $E_{\mathrm{Pt}} \mathrm{pH}$-meter-ionometer EXPERT001 was used. The compositions of the initial and reaction gas were determined during the experiment by gas chromatography $(3 \mathrm{~m} * 3 \mathrm{~mm}$ packed columns with activated carbon AP-3: determination of air, $\mathrm{CO}$, and $\mathrm{CO}_{2}$; separation temperature $160^{\circ} \mathrm{C}$, and $13 \mathrm{X}$ molecular sieves: determination of $\mathrm{O}_{2}, \mathrm{~N}_{2}$, and $\mathrm{CO}$; separation temperature $40^{\circ} \mathrm{C}$ ). In both cases fraction with particles size of $0.25-0.5 \mathrm{~mm}$ was used; the heat conductivity detector was also used, the carrier gas-argon. The reaction products were identified with the help of a chromatomass-spectrometry technique. Agilent Technologies gas chromatograph (USA) was used, equipped with mass-detector Agilent $5973 \mathrm{~N}$ (length of capillary column was $50 \mathrm{~m}$ and internal diameter $0.32 \mathrm{~mm}$, column was covered with polymethylsiloxan; thickness of a layer was 0.52 microns). The temperature of the evaporator was $150^{\circ} \mathrm{C}$, temperature of a column was programmed: 5 minutes temperature was supported at $50^{\circ} \mathrm{C}$, then during 12 minutes the temperature was lifted with speed of $15^{\circ} \mathrm{C} /$ minutes up to $230^{\circ} \mathrm{C}$, and then the given temperature was maintained 5 minutes more.

2.1. General Experiments Technique. Weighed portions of $\mathrm{KI}, \mathrm{PdI}_{2}$ and methanol were loaded consistently into the dry reactor thermostated at $40^{\circ} \mathrm{C}$ with electrodes inserted beforehand. The mixture was stirred during 20 minutes for dissolution of palladium salt. A reactor attached to a calibrated burette was pressurized and blown out with gas mixture $\mathrm{CO}$ and $\mathrm{O}_{2}$ (blown gas volume was not less than $500 \mathrm{~mL}$ ). The burette was used for measurement of the consumed gases volume. An initial gas mixture of carbon monoxide and oxygen was prepared in gasometer. Thermostated cell with saturated $\mathrm{KCl}$ solution connected to the reactor via an electrolytic bridge. Reaction solution was mixed, and $\mathrm{pH}$ and $E_{\mathrm{Pt}}$ values were measured. Then, without stop the stirring, a prepared beforehand methanol solution of alkyne was added with the help of a microsyringe through a liquid sampling unit, leading to total amount of solution up to $10 \mathrm{~mL}$. The moment of alkyne input was accepted as a start point of the experiment.

\section{Results and Discussion}

During experiments in the system $\mathrm{PdI}_{2}-\mathrm{KI}-\mathrm{CO}-\mathrm{O}_{2}-\mathrm{CH}_{3} \mathrm{OH}$ oscillations of platinum electrode potential $\left(E_{\mathrm{Pt}}\right)$ and $\mathrm{pH}$ values and also the characteristic step form of consumed gases $\left(\mathrm{CO}\right.$ and $\left.\mathrm{O}_{2}\right)$ curve (Figures 1 and 2) were obtained.

Oscillations, as one would expect for the closed system, had damped character and continued from 2 to 4 hours according to the experiment conditions. In MB carbonylation experiments the relaxation oscillations were observed frequently (see Figure 1) when the system was in the upper (oxidized) state for a long time, doing short-time transitions into the lower (reduced) state. In many experiments with $\mathbf{P}$ as a substrate it was necessary for oscillations initiation to enter into a system small amounts (5-15 mcL) of triethylamine, which led the system into a $\mathrm{pH}$ values range where the oscillations can begin. However, it is necessary to notice that the role of bases in oscillations development is not quite clear, and this question requires further researches. Oscillations in the system with MB began without adding of the base.

Gases consumption occurs in the portions at those moments only when the system passes in the reduced state; the bottom points on the $\mathrm{pH}$ and $E_{\mathrm{Pt}}$ change curves were corresponded to these states. In the rest of the time, which surpasses considerably the moments of products synthesis (reduced states), the system does not consume the gas mixture- to these states almost horizontal regions of gases consumption curves corresponded.

The several series of one-factorial kinetic experiments were carried out for the study of influence of reagents initial concentrations that were added into system. As a result of these experiments the area where the advanced oscillations develop was determined. The experiments with $\mathbf{M B}$ were carried out in interval $\left[\mathrm{PdI}_{2}\right]_{0}$ concentration from 0.0025 up to $0.02 \mathrm{M}$. The concentration of other reagents was maintained as follows: $[\mathrm{KI}]_{0}=0.4 \mathrm{M} ;[\mathrm{MB}]_{0}=0.1 \mathrm{M}$; 


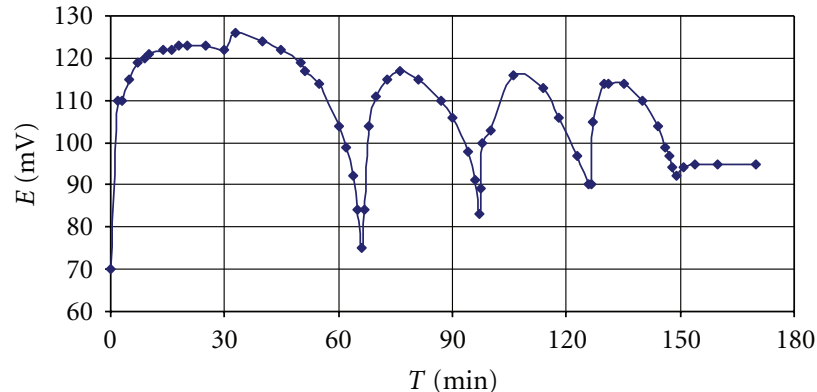

(a)

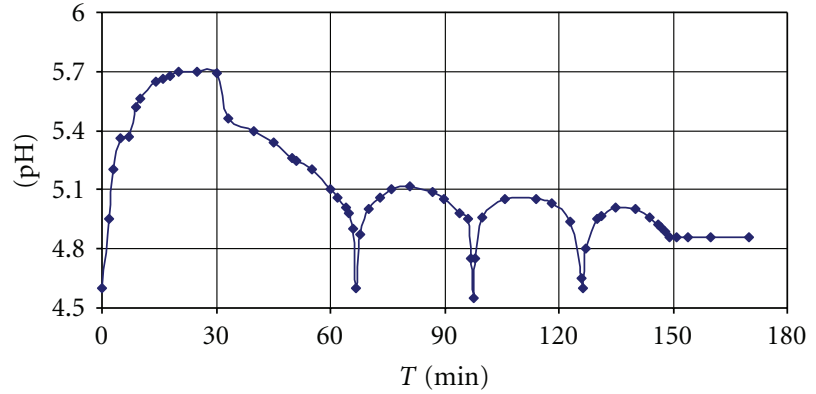

(b)

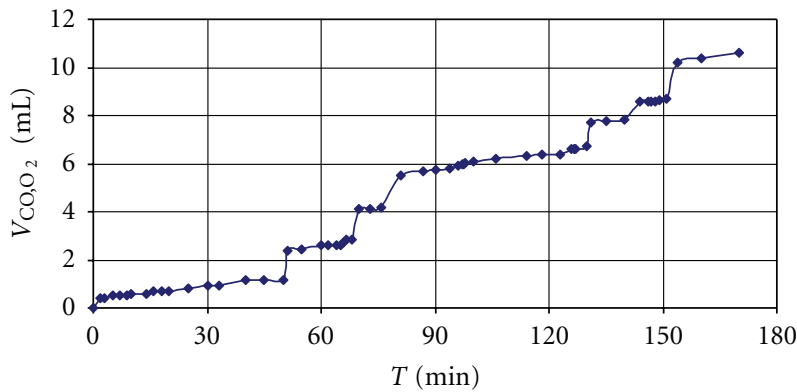

(c)

Figure 1: Oxidative carbonylation of 2-methyl-3-buthyne-2-ol $(\mathrm{MB})$ in the system $\mathrm{PdI}_{2}-\mathrm{KI}-\mathrm{CO}-\mathrm{O}_{2}-\mathrm{CH}_{3} \mathrm{OH} .[\mathrm{PdI}]_{0}=0,005 \mathrm{M} ;[\mathrm{KI}]_{0}=$ $0,4 \mathrm{M} ;[\mathrm{MB}]_{0}=0,1 \mathrm{M} ;[\mathrm{CO}]_{0}=60 \% ;\left[\mathrm{O}_{2}\right]_{0}=40 \%$.

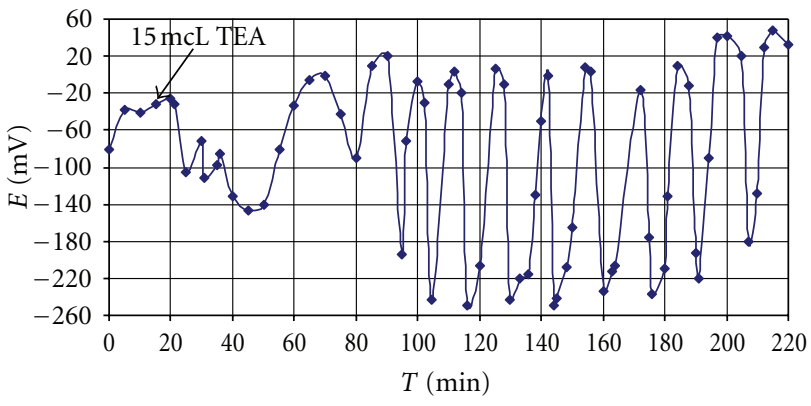

(a)

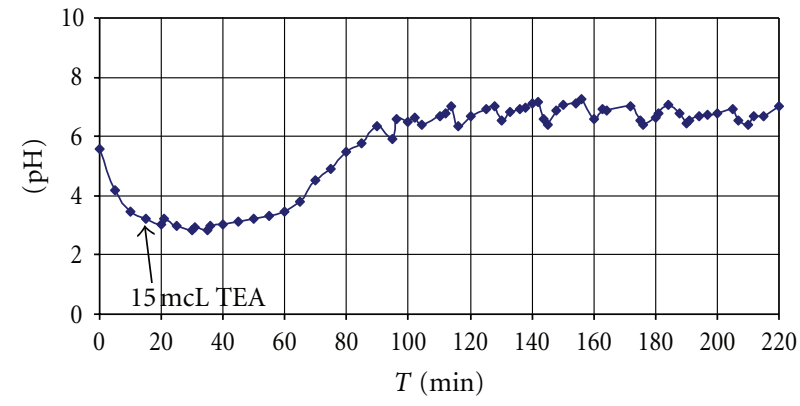

(b)

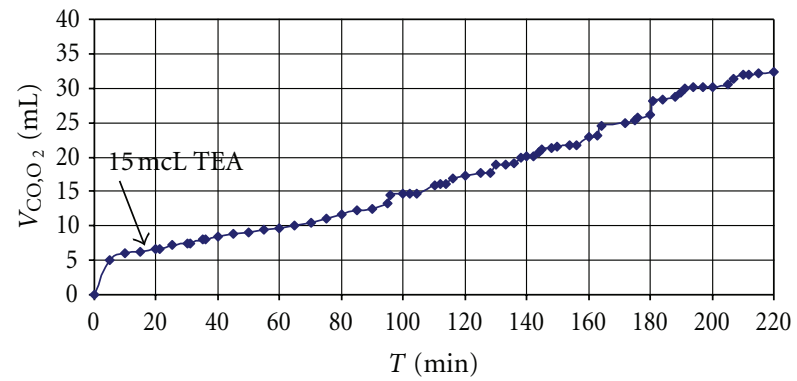

(c)

Figure 2: Oxidative carbonylation of 2-propyne-1-ol (P) in the system $\mathrm{PdI}_{2}-\mathrm{KI}-\mathrm{CO}-\mathrm{O}_{2}-\mathrm{CH}_{3} \mathrm{OH} .[\mathrm{PdI}]_{0}=0,015 \mathrm{M} ;[\mathrm{KI}]_{0}=0,4 \mathrm{M} ;[\mathrm{P}]_{0}=$ $0,1 \mathrm{M} ;[\mathrm{CO}]_{0}=60 \% ;\left[\mathrm{O}_{2}\right]_{0}=40 \%$. 


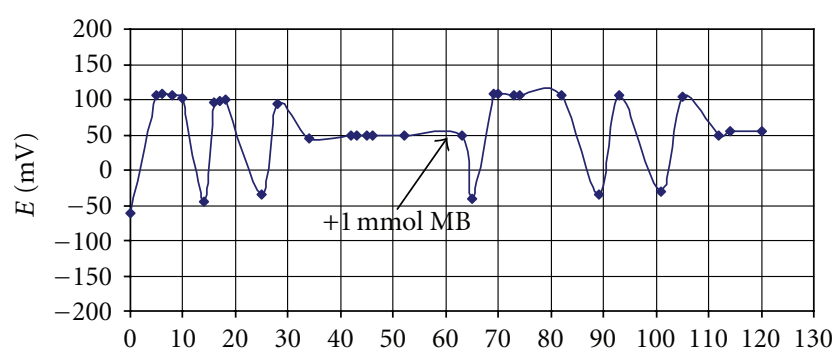

FIgure 3: Oxidative carbonylation of $\mathbf{M B}$ with input of an additional substrate portion. $[\mathrm{KI}]_{0}=0.4 \mathrm{M} ;\left[\mathrm{PdI}_{2}\right]_{0}=0.01 \mathrm{M} ;[\mathrm{MB}]_{0}=$ $0.1 \mathrm{M} ;[\mathrm{CO}]_{0}=72 \% ;\left[\mathrm{O}_{2}\right]_{0}=21 \% ;\left[\mathrm{N}_{2}\right]_{0}=7 \%$.

$[\mathrm{CO}]_{0}:\left[\mathrm{O}_{2}\right]_{0}=3: 2$. The period of oscillations increases with the reduction of $\left[\mathrm{PdI}_{2}\right]_{0}$ concentration up to $0.0025 \mathrm{M}$ while their amplitude does not vary practically. $E_{\mathrm{Pt}}$ values are ranged in interval $(-60) /(+130) \mathrm{mV}$. The reduction of oscillations number and also their amplitudes is observed at increasing of $\left[\mathrm{PdI}_{2}\right]_{0}$ concentration up to $0.02 \mathrm{M}$; at $\left[\mathrm{PdI}_{2}\right]_{0}$ concentration of $0.02 \mathrm{M}$ oscillations are practically away, which can attest a hypothesis about approach to the upper border of concentrations area where the oscillatory mode is realized. Study of gas mixture composition influence on oscillations appearance was carried out at compositions of gas mixture from $44 \% \mathrm{CO}\left(56 \% \mathrm{O}_{2}\right)$ up to $94 \% \mathrm{CO}\left(6 \% \mathrm{O}_{2}\right)$. Moderate increase of amplitude and period of oscillations is marked at the increase of initial CO concentration. The oscillations are not found out at concentration of $\mathrm{CO}$ in a gas mixture less than $44 \%$ and more than $94 \%$. Also in the case of oxidative carbonylation of phenylacetylene and methylacetylene $[6,7]$, it was shown that alkyne portion addition (1 mmol e.g., MB) after the termination of an initial series of oscillations results in their renewal (Figure 3).

It can be testified that the reasons of oscillations attenuation are connected with substrate consumption and they could be not damping in case of its continuous feeding.

The oscillations area determined in experiments with $\mathbf{P}$ range in concentration interval for $[\mathrm{KI}]_{0}-$ from 0.20 up to $0.45 \mathrm{M}$, for $\left[\mathrm{PdI}_{2}\right]_{0}$-from 0.005 up to $0.035 \mathrm{M}$, for $[\mathrm{CO}]_{0}$, from 60 up to $93 \%$ (vol). An obviously expressed dependence of oscillations appearance on the presence in system thriethylamine at $[\mathbf{P}]_{0}$ not less than $0.6 \mathrm{M}$ was observed. The oscillations with the alternation of different periods was noticed during some experiments that can serve as indirect confirmation of two different processes proceeding in the system in parallel. It is quite possible that such processes are the reaction of oxidative and additive carbonylation.

3-Hydroxy-3-methyl-butan-1-on and methyl ester of 3methyl-2-butenic acid were found out among the products of $\mathbf{M B}$ oxidative carbonylation. The basic products of $\mathbf{P}$ carbonylation in the given conditions are dimethyl esters of itaconic, 2-pentyn-1,5-dioic, and 2-methoxy-2-pentendioic acids. Considering the literary data mentioned above and also the experiments results of alkynes carbonylation studying in homogeneous catalytic systems [4, 6, 7, 9-11], it is possible to offer some connected routes where the products found out by us could be formed.

$$
\begin{aligned}
& \text { 1) } \mathrm{CO}+1 / 2 \mathrm{O}_{2} \longrightarrow \mathrm{CO}_{2} \\
& \text { 2) } \mathrm{HC} \equiv \mathrm{CCH}_{2} \mathrm{OH}+2 \mathrm{CO}+2 \mathrm{CH}_{3} \mathrm{OH} \longrightarrow \mathrm{CH}_{2}=\mathrm{C} \underset{\mathrm{COOCH}_{3}}{\mathrm{CH}_{2} \mathrm{COOCH}_{3}}+\mathrm{H}_{2} \mathrm{O} \\
& \text { 3) } \mathrm{HC} \equiv \mathrm{CCH}_{2} \mathrm{OH}+2 \mathrm{CO}+2 \mathrm{CH}_{3} \mathrm{OH}+1 / 2 \mathrm{O}_{2} \longrightarrow \mathrm{CH}_{3} \mathrm{OCOC} \equiv \mathrm{CCH}_{2} \mathrm{COOCH}_{3}+2 \mathrm{H}_{2} \mathrm{O} \\
& \text { 4) } \underset{\mathrm{CH}}{\mathrm{CH}_{3} \mathrm{OCC}} \equiv \mathrm{CCH}_{2} \mathrm{COOCH}_{3}+\mathrm{CH}_{3} \mathrm{OH} \stackrel{[\mathrm{Pd}]}{\longrightarrow} \underset{\mathrm{O}}{\mathrm{CH}} \stackrel{\mathrm{OCH}_{3} \mathrm{OC}(\mathrm{O}) \mathrm{C}}{=} \mathrm{CHCH}_{2} \mathrm{COOCH}_{3}
\end{aligned}
$$

The offered scheme implies presence in the system of several connected processes: reactions of oxidation $\mathrm{CO}$ up to $\mathrm{CO}_{2}$, reactions of $\mathbf{P}$ additive carbonylation up to dimethyl ester of itaconic acid, and reactions of $\mathbf{P}$ oxidative carbonylation up to two other acids esters. Such reaction run was unexpected, as the other reactions investigated by us earlier in similar systems $\left(\mathrm{KI}-\mathrm{PdI}_{2}-\mathrm{CO}-\mathrm{O}_{2}\right.$-phenylacetylene or methylacetylene; $\mathrm{LiBr}-\mathrm{PdBr}_{2}-\mathrm{CO}-\mathrm{O}_{2}$-phenylacetylene or methylacetylene; $\left.\mathrm{LiBr}-\mathrm{PdBr}_{2}-\mathrm{H}_{2} \mathrm{O}-\left(\mathrm{CH}_{3}\right)_{2} \mathrm{CO}-\mathrm{CO}\right)[3,4,6$, 7] have been concerned with for processes of alkynes oxidative (only) carbonylation.

\section{Conclusion}

In the given work the oscillatory mode in oxidative carbonylation reaction of two new substrates-2-methyl-3-butyn-2-ol and 2-propyn-1-ol-for the first time was found out.
The data, which have been found out in experiments with 2propyn-1-ol, allow to consider that alongside the alkyne oxidative carbonylation in the system its additive carbonylation proceeds. The ranges of reagents initial concentrations and gas mixtures compositions were determined at which $E_{\mathrm{Pt}}$ and $\mathrm{pH}$ values steady oscillations were observed. It was shown that a new portion of alkyne adding results in recurrence of an oscillatory mode. Thus, it is possible to assert that the first examples of nonlinear behavior of a new class of oscillatorsreactions of alkynoles oxidative carbonylation - were found out.

\section{Acknowledgment}

This work was supported by the Russian Foundation for Basic Research (Project no. 05-03-33151-a; 09-03-01072-a). 


\section{References}

[1] R. J. Field and M. Burger, Eds., Oscillations and Travelling Waves in Chemical Systems, John Wiley \& Sons, New York, NY, USA, 1985.

[2] M. M. Slin'ko and N. I. Jaeger, "Oscillating heterogeneous catalytic systems," in Studies in Surface Science and Catalysis, B. Deimon and J. T. Yates, Eds., vol. 86, Elsevier Science, Amsterdam, The Netherlands, 1994.

[3] G. M. Shul'akovsky, O. N. Temkin, N. V. Bykanova, and A. N. Nyrkova, "Chemical kinetics," in Catalysis: Kinetic Models of Liquid-Phase Reactions, p. 112, IPC, Chernogolovka, Russia, 1985.

[4] A. V. Malashkevich, L. G. Bruk, and O. N. Temkin, "New oscillating reaction in catalysis by metal complexes: a mechanism of alkyne oxidative carbonylation," Journal of Physical Chemistry A, vol. 101, no. 51, pp. 9825-9827, 1997.

[5] L. G. Bruk, I. V. Oshanina, A. S. Zakieva, A. P. Kozlova, and O. N. Temkin, "Critical phenomena in homogeneous catalytic reaction of acetylene carbonylation to maleic anhydride," Kinetics and Catalysis, vol. 39, no. 2, pp. 167-172, 1998.

[6] S. N. Gorodskii, A. N. Zakharov, A. V. Kulik, L. G. Bruk, and O. N. Temkin, "Oxidative carbonylation of alkynes in an oscillation mode: I. concentration limits for oscillations in the course of phenylacetylene carbonylation and possible mechanisms of the process," Kinetics and Catalysis, vol. 42, no. 2, pp. 251-263, 2001.

[7] S. N. Gorodskii, E. S. Kalenova, L. G. Bruk, and O. N. Temkin, "Oxidative carbonylation of alkynes in self-oscillating mode. Effect of the nature of substrates on the dynamic behavior of reaction system," Russian Chemical Bulletin, vol. 7, pp. 15341543, 2003.

[8] S. N. Gorodsky, A. V. Kurdiukov, and O. N. Temkin, "ICC 14 pre-symposium," in Proceedings of the International Symposium on Creation and Control of Advanced Selective Catalysis as the Celebration of the 50th Anniversary of the Catalysis Society of Japan, p. 39, Japan, Kyoto, 2008.

[9] S. N. Gorodsky and A. V. Kurdiukov, "Oxidative carbonylation of dimethylethinylcarbinol in oscillatory mode," Review MITHT, vol. 3, no. 3, pp. 85-88, 2008 (Russian).

[10] S. N. Gorodsky, A. V. Kurdiukov, and O. N. Temkin, "Oscillating regime in the propargyl alcohol carbonylation reaction," Review MITHT, vol. 5, no. 1, pp. 35-41, 2008 (Russian).

[11] S. N. Gorodsky, L. G. Bruk, A. E. Istomina, A. V. Kurdiukov, and O. N. Temkin, "Alkynes carbonylation reactions in solutions of palladium complexes as a new class of oscillatory processes," Topics in Catalysis, vol. 52, no. 6-7, pp. 557-562, 2009.

[12] E. D. Bergmann and E. Zimkin, "The reaction of nickel carbonyl with ethynyldimethylcarbinol and isopropenylacetylene," Journal of the Chemical Society (Resumed), pp. 34553457, 1950.

[13] J. Tsuji and T. Nogi, "Organic synthesis by means of noble metal compound XXIV. Palladium-catalyzed carbonylation of propargyl alcohols and propargyl chloride," Tetrahedron Letters, vol. 7, no. 16, pp. 1801-1804, 1966.

[14] N. S. Zefirov, Chemical Encyclopedia, vol. 5, Great Russian Encyclopedia, Moscow, Russia, 1998.

[15] E. R. H. Jones, T. Y. Shen, and M. C. Whiting, "Researches on acetylenic compounds. Part XXII. The reaction between nickel carbonyl and monosubstituted acetylenic compounds," Journal of the Chemical Society, pp. 230-236, 1950.

[16] R. W. Rosenthal, L. H. Schwartzman, N. P. Greco, and R. Proper, "Carboxylation of propargyl alcohol," Journal of Organic Chemistry, vol. 28, no. 10, pp. 2835-2838, 1963. 


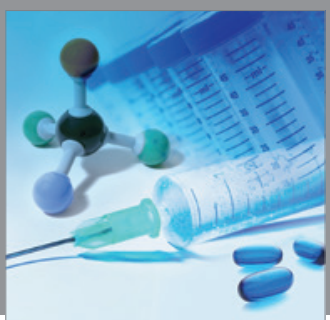

International Journal of

Medicinal Chemistry

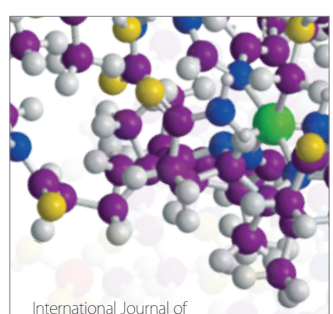

Carbohydrate Chemistry

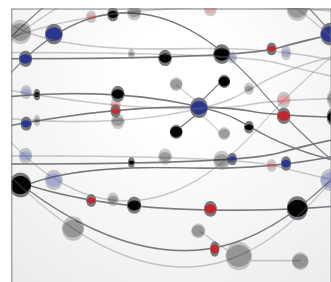

The Scientific World Journal
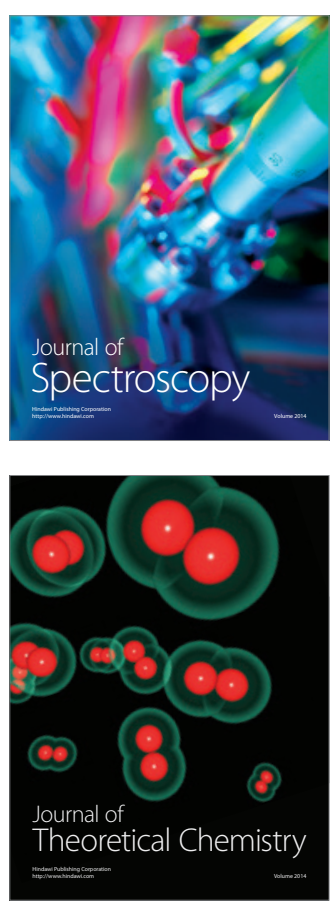
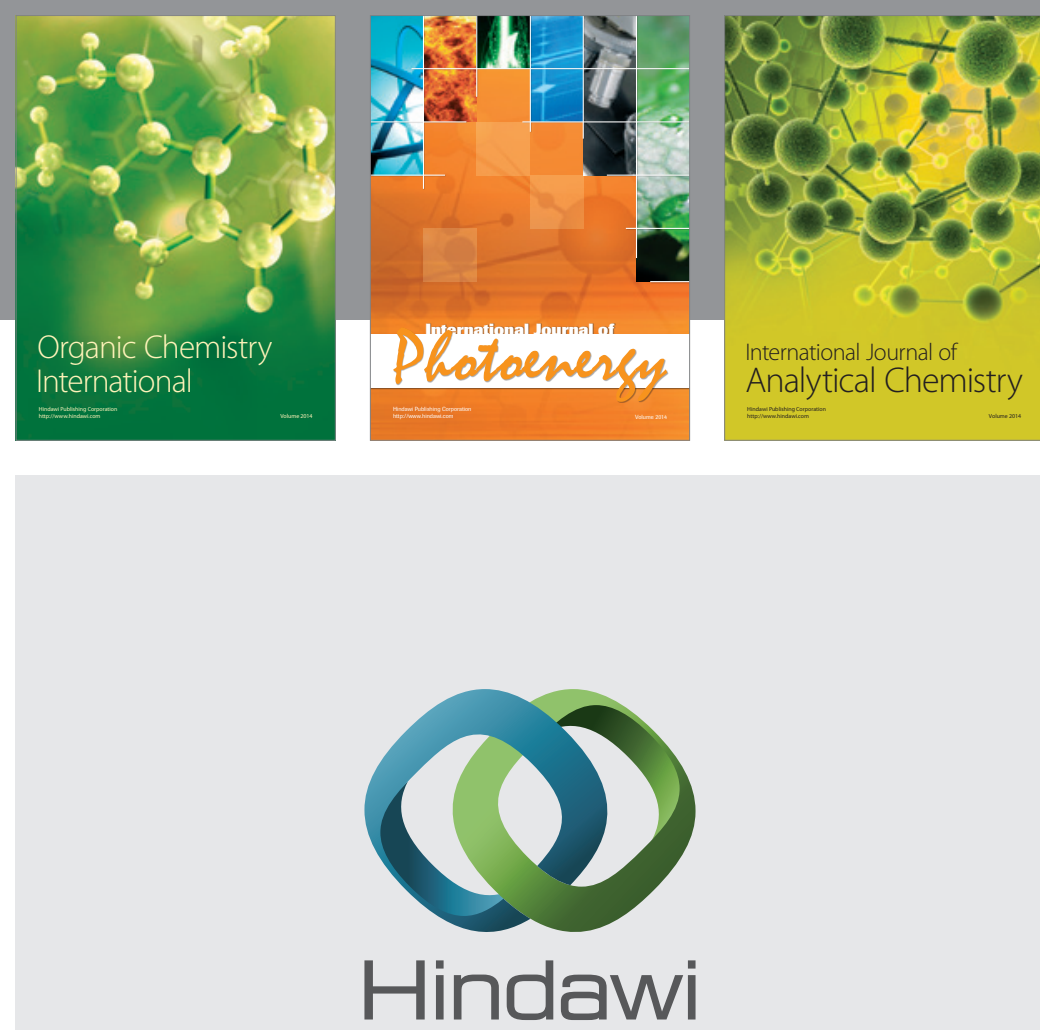

Submit your manuscripts at

http://www.hindawi.com
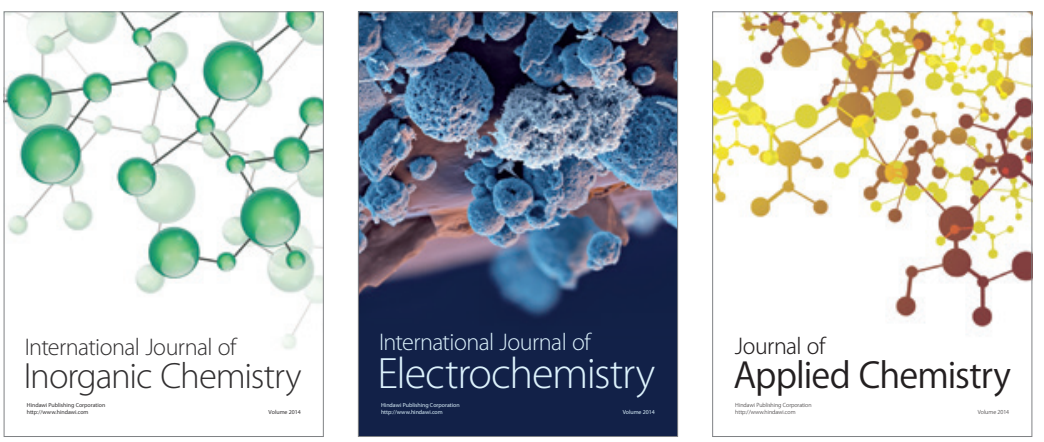

Journal of

Applied Chemistry
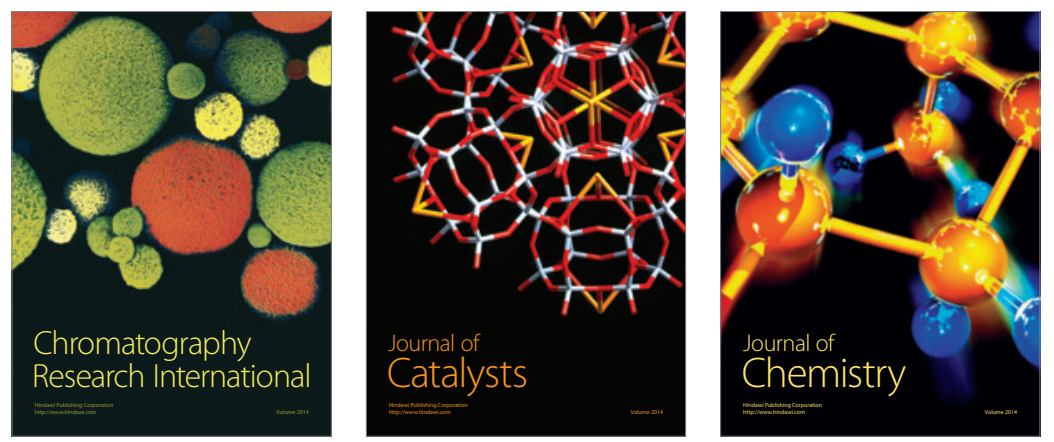
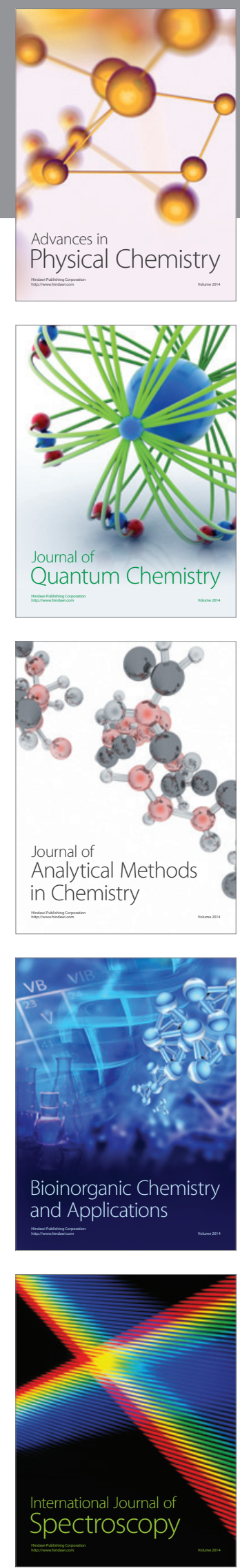